\title{
Thermodynamic cycles variability of TJI gas engine with different mixture preparation systems
}

Gas engines are a viable source of propulsion due to the ecological indicators of gas fuels and the large amount of the needed natural resources. Combustion of lean homogeneous gas mixtures allows achieving higher thermal efficiency values, which is a key factor in current engine development trends. Using the spark-jet ignition system (also called as Turbulent Jet Ignition or two-stage combustion) significantly improves the efficiency and stability of the combustion process, especially in the part-load operation on lean or very lean mixtures. This paper presents the impact of using two different fuel injection methods: Port Fuel Injection or mixer on the operation stability of a gas engine designed for LDVs.

Comparative studies of two different mixture preparation systems were carried out on a single-cylinder AVL 5804 test engine. By recording the cylinder pressure for a significant number of engine cycles, it became possible to determine the repeatability of engine operation and to correlate the results with the mixture formation system and the air-fuel ratio. In the performed research the beneficial effect of the mixer system application on the engine operation stability in the part-load conditions was found.

Key words: CNG engine, cycle variations, Turbulent Jet Ignition, two-stage combustion, gas mixture formation

\section{Introduction}

Actually the most common energy sources supplied to internal combustion engines are liquid fuels derived from crude oil. This reliance on one type of resource encourages the search for alternative motor fuels, which are characterized by wide availability, low production costs and better ecological indicators. Natural gas seems to be an attractive alternative, whose reserves are estimated to be more than twice as high as the crude oil reserves [9]. The composition of natural gas strongly depends on where it was extracted from $[2,5]$; however, regardless of this, the main component is always natural gas (methane, $\mathrm{CH}_{4}$ ). Natural gas can be obtained from several sources, and its production is profitable due to the low production cost [10].

Methane has a low $\mathrm{C} / \mathrm{H}$ ratio, thanks to which $\mathrm{CO}_{2}$ emissions during combustion are reduced by about $25 \%$ when considered in TTW, along with a significant decrease in particulate emissions compared to gasoline [9].

An effective method of improving the ecological and energy indicators of a single-fuel gas engine is the use of lean mixtures combustion. However, such mixtures require large ignition energy, which can be obtained, for example, by using a divided combustion chamber or spark-jet ignition $[13,14,21]$.

Gaseous fuel can be supplied to the engine through a mixer, fuel injection to the intake port (PFI) or using direct injection (DI). As a rule, mixer systems are being installed in heavy duty engines, while multi-point injection systems (PFI-type) are being used in LDVs. Each system has a different method of creating the mixture, which directly translates into different engine performance [8].

Research carried out in the scope of the repeatability of gas engine working cycles with a conventional ignition system indicated a decrease in work stability with an increasingly leaner mixture [15]. Singotia et al. [18] also noted a decrease in operation stability when increasing the engine speed, but when the load increased so did the stability.

Comparison of direct and indirect fuel injection solutions [19] indicated the essential role of the injection tim- ing, which directly translates into the amount of time available for mixture formation. A lower $\mathrm{COV}_{\text {IMEP }}$ value was obtained in the whole analyzed range of fuel injection timing $\left(330-120^{\circ} \mathrm{CA}\right.$ bTDC) when using PFI injection. The disadvantage of this solution is the decrease in volumetric efficiency. Further research [11] conducted for lean gas combustion $(\Phi=1 / \lambda=0.75-1.00)$, indicated a more stable engine operation and greater thermal efficiency when using indirect injection for high engine loads. Direct injection provides better indicators when operating on partial loads.

Patel et al. [12] compared the direct CNG injection and the throttle body integrated mixer in relation to the engine speed. Higher thermal efficiency was achieved by using the mixer in the low engine speed range, while direct injection proved better when over $1500 \mathrm{rpm}$.

The impact of mixer design on the cycle operation repeatability in a six-cylinder in-line engine was discussed in [3]. Supplying of gas through cross beams placed perpendicular to the mixer axis was compared, relative to the circumferential arrangement in the case of lean combustion $(\lambda=1.7)$. The lower mean coefficient of cycle variation in all cylinders was observed for the mixer with nozzles placed radially.

A two-stage combustion system, which was also the subject of this paper, has been in development since the 1920 s all the way to the present day. The main purpose of its application is to obtain large ignition energy, which is particularly important when burning lean mixtures. Due to the prospects of implementing the solution on a large scale, various construction variants have been proposed [22].

The use of this type of system allows increasing the limits of stable engine operation $\left(\mathrm{COV}_{\text {IMEP }}<5\right)$ in conditions of lean mixtures combustion as compared to a conventional system with open geometry combustion chamber [16]. In addition, it significantly intensifies the combustion process, which is particularly important due to the slower laminar flame speed of natural gas compared to gasoline [1, 4]. 


\section{Aim and scope of research}

The use of a spark-jet ignition system in a single-fuel gas engine results in a change of the nature of the combustion process when compared to the conventional (SI) solution. In the analyzed case, the engine was fed with a premixed fuel-air mixture. The degree of mixture homogeneity depends mainly on the method of its preparation. Hence, various methods of gaseous fuel injection are used. The purpose of the research described in this paper is to assess the impact of various CNG supply methods on the operation stability of an engine with an additionally supplied prechamber.

The scope of research reported here includes conducting an experiment on a test stand equipped with a singlecylinder test engine. In the tests engine parameters with two different CNG injection systems were recorded: gas delivery by PFI system and by gas-air mixer, as described later in chapter 3.3. In both cases however, the small ignition gas quantity was supplied by jet igniter mounted in small prechamber located in the center of cylinder head (s.c. active pre-chamber).

\section{Methodology of research}

\subsection{Test stand}

To measure the impact of the combustible mixture homogeneity on the gas engine operation stability, a test stand equipped with a single-cylinder AVL 5804 engine was used, with its technical data listed in Table 1 . The modernization of the engine cylinder head, which was previously used as a dual fuel system, allowed the use of a Turbulent Jet Ignition system. The jet igniter (Fig. 1) consists of a small volume pre-chamber, a housing with a spark plug and a direct gas injection system. Gas is dispensed to the ignition chamber through the injector connected to the prechamber with a tube ended with a check valve. The chamber has 10 nozzles, 7 were placed radially, while 3 were placed in the cylinder axis.

The engine was connected to an asynchronous brake operating in the range of $-50-300 \mathrm{Nm}$ and ensuring that the engine operates at as constant a speed as possible. The cooling and lubrication system (AVL 577) works independently of the engine speed. It allows obtaining stable thermal conditions up to the water and oil temperature of $150^{\circ} \mathrm{C}$.

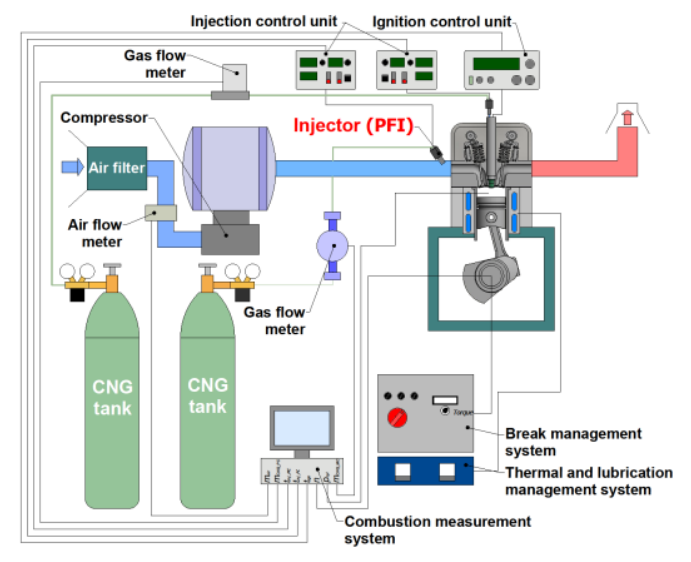

Fig. 2. Schematic of single cylinder engine test stand with port fuel injection system (PFI)
During the tests, the test stand was used in two configurations described in Figs 2 and 3. The difference concerned the system for creating the main combustible mixture. In the first test series, gas injection to the intake manifold (PFI) was used, while in the second, the mixer (M) was used. The intake system was equipped with a supercharging device that allowed smooth pressure regulation in the intake manifold. It consisted of an electric motor driven mechanical compressor and an expansion tank. The exhaust system did not contain any aftertreatment systems.

The CNG tank consisted of two cylinders with pressure reducers, which supplied with gas the igniter and main chamber independently. This made it possible to obtain different injection pressures for those two. Two independent manually adjusted controllers were used to control the injection system operation. They allowed regulating of the start time and duration of fuel injection in a wide range. The ignition time and coil charging current were also adjusted manually.

Table 1. Engine technical data

\begin{tabular}{|l|c|}
\hline Engine & single cylinder AVL 5804 \\
\hline Displacement volume & $510.7 \mathrm{~cm}^{3}$ \\
\hline Bore $\times$ stroke & $85 \times 90 \mathrm{~mm}$ \\
\hline Pre-chamber volume & $1.8 \mathrm{~cm}^{3}$ \\
\hline Compression ratio & 15.2 \\
\hline Piston bowl shape & omega $\omega$ \\
\hline Cooling system & liquid \\
\hline Boosting system & mechanically driven supercharger \\
\hline
\end{tabular}

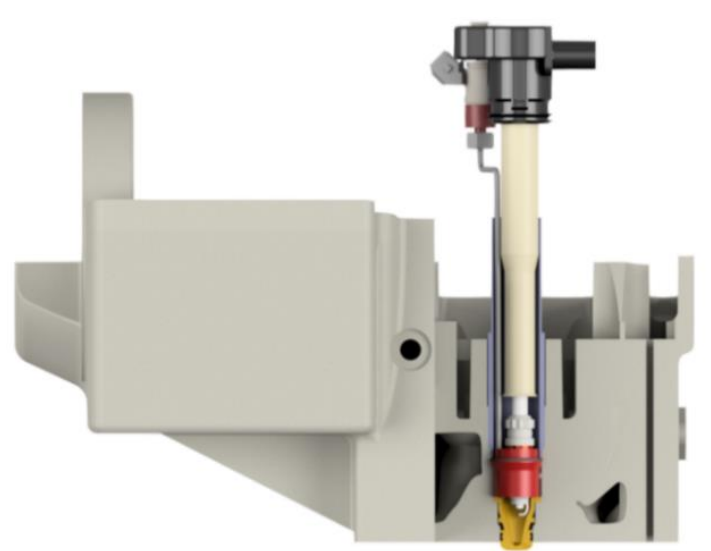

Fig. 1. Cross-section view of jet igniter mounted in AVL 5804 cylinder head

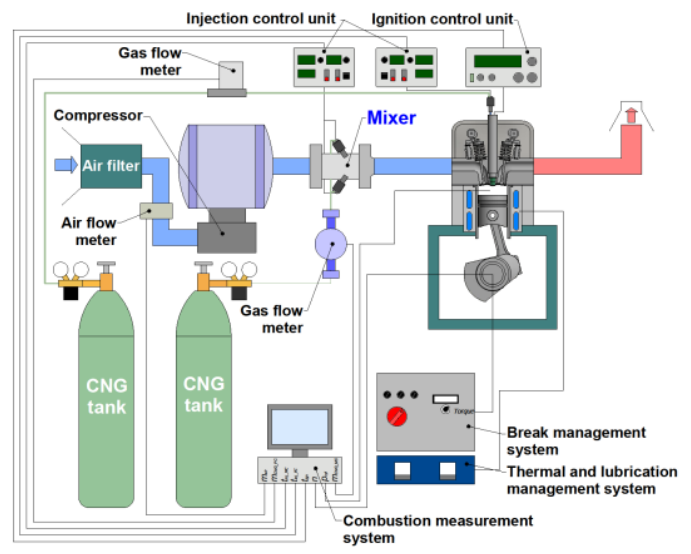

Fig. 3. Schematic of single cylinder engine test stand with mixer (M) injection system 


\subsection{Methodology and research conditions}

The AVL IndiSmart fast variable parameter registration system was used in the research. The data was processed on an ongoing basis using the AVL IndiCom software. The pressure was measured using an AVL GH14D piezoelectric transducer with a measuring range of $0-250$ bar mounted in the engine cylinder head. The engine speed was recorded using an optical crank angle marker AVL 364C. The mass air and CNG flow rates were measured by three flow meters with different working ranges, whose exact parameters were provided in Table 2. Based on the data of the amount of CNG supplied, the fuel doses per cycle dispensed to the cylinder $\left(\mathrm{q}_{\mathrm{oMC}}\right)$ and to the pre-chamber $\left(\mathrm{q}_{\mathrm{oPC}}\right)$ were determined. The air-fuel equivalence ratio $\lambda$ was calculated according to formula (1). Its value was adjusted by changing the pressure in the intake system, which led to a change in the mass air flow rate. Fuel injection time and ignition time were read using clamp meters.

$$
\lambda=\frac{\dot{\mathrm{m}}_{\text {air }}}{\left(\dot{\mathrm{m}}_{\text {fuel_PC }}+\dot{\mathrm{m}}_{\text {fuel_MC }}\right) \times \mathrm{L}_{\mathrm{t}}}
$$

Tests for both injection systems were carried out under the same conditions. The parameter that changed during the engine operation was the value of the air-fuel equivalence ratio, as it varied in the range 1.2-1.55. Data was recorded for three engine operating points at $1500 \mathrm{rpm}$. The total amount of fuel per cycle was constant during testing and the load was about 7 bar of IMEP. The gas injection start time for both chambers was the same at $300^{\circ} \mathrm{CA}$ bTDC in the intake stroke. Ignition was determined individually at individual work points. The ignition timing was adjusted so that the $\mathrm{COC}$ was located $8^{\circ} \mathrm{CA}$ aTDC. The COC was assumed to be the camshaft angle for which $50 \%$ of the fuel dose was burned, MBF50\%, and was calculated based on the integral of heat released.

Table 2. Mass flow meters technical data

\begin{tabular}{|l|c|c|}
\hline Parameter & Name & Specification \\
\hline Air mass flow & Sensycon Sensyflow & $0-720 \mathrm{~kg} / \mathrm{h}( \pm 1 \%)$ \\
\hline $\begin{array}{l}\text { Main chamber } \\
\text { fuel mass flow }\end{array}$ & Emerson mCMFS & $0.1-2 \mathrm{~kg} / \mathrm{h}( \pm 0.25 \%)$ \\
\hline $\begin{array}{l}\text { Pre-chamber fuel } \\
\text { mass flow }\end{array}$ & Bronkhorst 111B & $0.1-100 \mathrm{~g} / \mathrm{h}( \pm 0.5 \%)$ \\
\hline
\end{tabular}

During the tests, the parameters for 100 following engine cycles were recorded at a frequency of $0.1^{\circ} \mathrm{CA}$. To qualitatively determine the repeatability of engine operation from cycle to cycle, COV values were determined according to formula (2). It determined the measure of the degree of variation in the value of the measured variable.

$$
\operatorname{COV}_{\text {value }}=\frac{\sigma_{\text {value }}}{\mu_{\text {value }}}
$$

where $\sigma_{\text {value }}$ is the standard deviation:

$$
\sigma_{\text {value }}=\sqrt{\frac{\sum_{\mathrm{i}=1}^{\mathrm{N}}\left(\mathrm{x}_{\mathrm{i}}-\overline{\mathrm{x}}\right)^{2}}{\mathrm{~N}}}
$$

and $\mu_{\text {value }}$ is the arithmetic average:

$$
\mu_{\text {value }}=\frac{1}{N} \sum_{i=1}^{N} x_{i}
$$

\subsection{Injection methods}

A gas engine with an additional combustion chamber requires at least two fuel supply systems. In the analyzed case, direct fuel injection into the ignition chamber was used, as well as either an external PFI or a mixing system. The specification of the solutions used during the tests was shown in Table 3. In order to obtain a low dose of $\mathrm{q}_{\mathrm{oPC}}$ a choking system was installed between the injector and the pipe supplying fuel to the pre-chamber.

Table 3. Gas injection systems specification

\begin{tabular}{|c|c|c|c|c|}
\hline Apply & Type & $\begin{array}{c}\text { Injector } \\
\text { quantity }\end{array}$ & $\begin{array}{c}\text { Injection } \\
\text { pressure }\end{array}$ & Fuel dose $[\mathrm{mg} / \mathrm{inj}]$ \\
\hline PC & DI & 1 & 6 bar & 0.38 \\
\hline MC & PFI & 1 & 9 bar & 19.9 \\
\hline MC & Mixer & 4 & 9 bar & 19.9 \\
\hline
\end{tabular}

PFI injection was carried out using a single dedicated electromagnetic injector for CNG supply. It was placed so that the fuel was injected into one of the cylinder head's inlet port. The second system used a mixer built into the intake system at a considerable distance from the engine head. Mixer (Fig. 4) consisted of the housing (2), in which four injectors (3), fuel supply rails (4) and throttle (1) were placed. The body had a network of channels supplying fuel to the nozzle located circumferentially and in crossed beams.

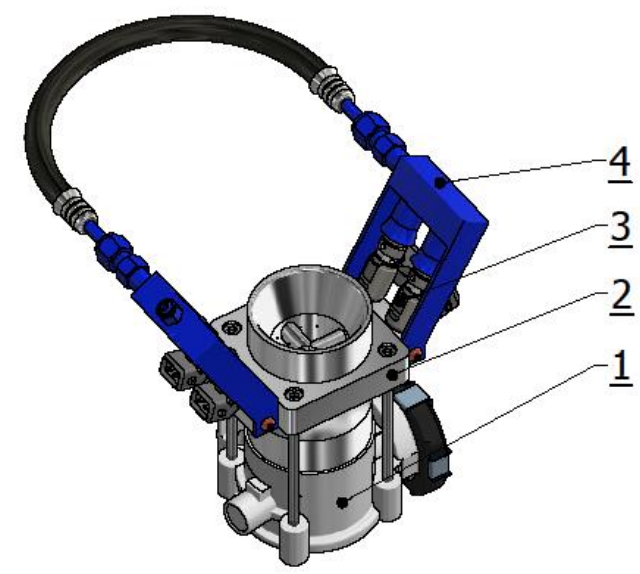

Fig. 4.View of 3D mixer model used in research

\section{Discussion of results}

Depending on the literature sources, researchers performing similar work used different numbers of recorded engine cycles [7, 17]. Due to the low level of values dispersion for the measured parameters, 100 cycles were deemed a sufficient number for the considered engine tests. The obtained data was presented in a general way as statistical data as well as in a more detailed way. The studies compared external systems for creating an air-fuel mixture, ensuring different quality of the obtained mixture. The airfuel equivalence ratio $\lambda$ varied in the range 1.2 to $1.55 \mathrm{du}$ ring the performed tests. This is due to the specific benefits of lean mixtures combustion.

Figure 5 presents a series of recorded pressure curves for the cylinder as a function of crankshaft angle at the maximum value of the air-fuel equivalence ratio $\lambda=1.55$. Data for the PFI system are marked in red, and data for the 
mixer system $(\mathrm{M})$ are blue. The maximal and minimal peak of pressure for all cycles is specified as a $\mathrm{P} \_$max and P_min. Greater divergence of values was found for the fuel injection into the intake duct. This system ensures worse mixing of the gaseous fuel with air, if only due to the smaller amount of time available. A significant part of the mixture formation process takes place directly in the cylinder during the intake and compression strokes. In comparison, while applying the mixer system the formation of the mixture begins in the intake system at a considerable distance from the engine head and much more time is available for better mixture homogenization. In addition, gas and air diffusion was supported by the mixer geometry.
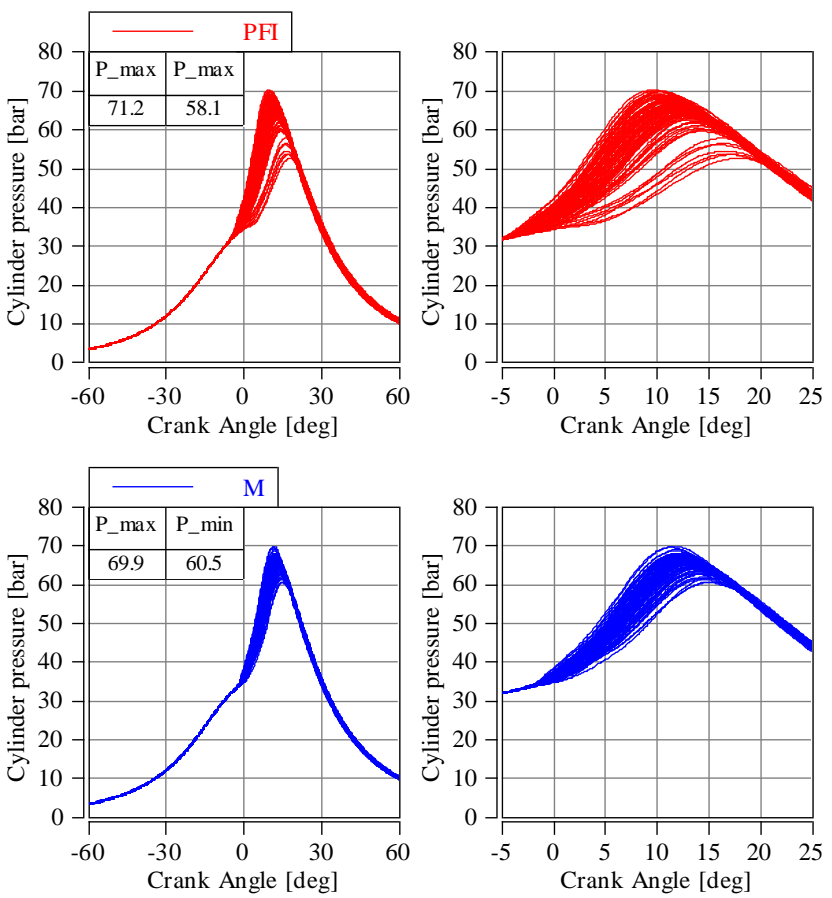

Fig. 5. Dispersion of in cylinder pressure trace for equivalence ratio $\lambda=1.55$, PFI marked in red, mixer system in blue

The parameter most commonly used to determine the engine operation stability is the coefficient of variation of the indicated mean effective pressure $\mathrm{COV}_{\text {IMEP }}$ [20], the results of which were shown in Fig 6. The limit value above which the engine is operating incorrectly is being accepted $5 \%$ [6]. In the case of gas engines, this is a particularly important parameter when determining the effective flammability limits of an air-fuel mixture. In the analyzed case, the lowest value was achieved for $\lambda=1.35$; below and above this value the $\operatorname{COV}_{\text {IMEP }}$ increases. This is probably related to the dependence of the laminar flame velocity on the composition of the combustible mixture.

One should keep in mind that the fuel dose delivered to the ignition chamber was small due to this being the most energy efficient way. As one can observe in the Fig. 6, in the whole analyzed range, more stable operation was obtained using a mixer.

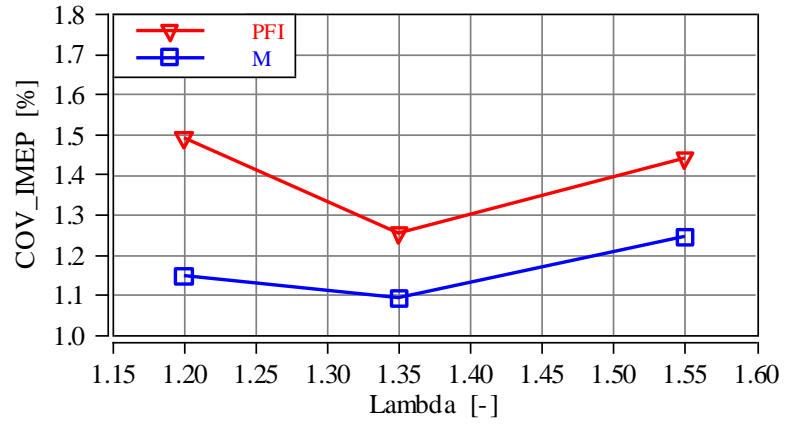

Fig. 6. Effects of injection system on coefficient of variation of indicated mean effective pressure (IMEP) for different charge composition

Figure 7 shows the distribution of the number of cycles in which IMEP falls within a given range for three selected $\lambda$ values. In the case of the leanest mixture, larger IMEP values were obtained by using injection before the intake valve. Then, along with the decreasing value of $\lambda$, the IMEP value increased in favor of the mixer system. This is probably due to the loss of the fresh fuel dose generated by the mixer when the timings overlapped. The air-fuel equivalence ratio increased by increasing the pressure in the intake system, which promoted the flow of fresh fuel dose remaining from the previous cycle directly to the exhaust system.
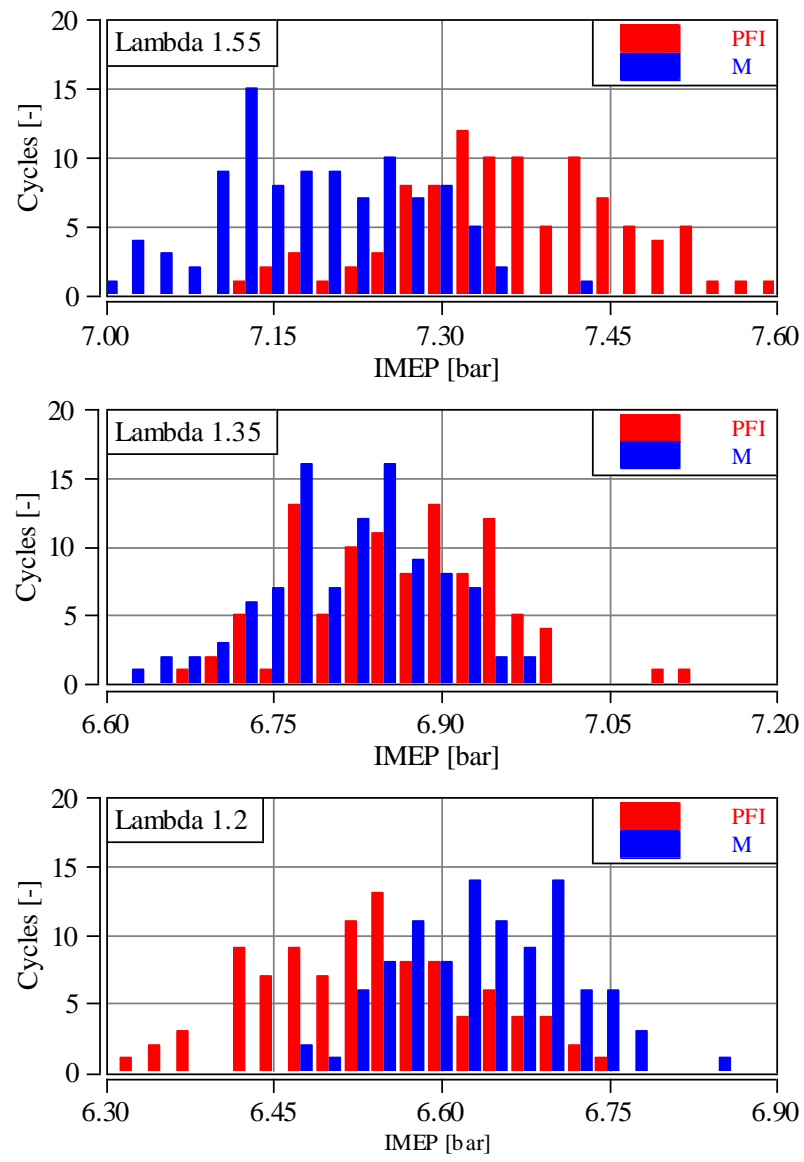

Fig. 7. Histogram of indicated mean effective pressure for three different lambda values

The maximum pressure in the cylinder was then taken into account, as well. This is one of the important indicators 
of the intensity and regularity of the combustion process. According to the results presented in Fig. 8, in the entire $\lambda$ range, as it was in the case of $\mathrm{COV}_{\text {IMEP }}$, gas injection through the mixer provides greater engine operation stability. The characteristic shape of both curves varied. In the case of the PFI system, as the dose becomes leaner, the $\mathrm{COV}$ increases, i.e. the repeatability of individual work cycles decreases. The use of the mixer significantly stabilizes the combustion process especially in the range of $\lambda=$ $=1.2-1.35$. The largest difference of $3 \%$ was recorded for the leanest mixture.

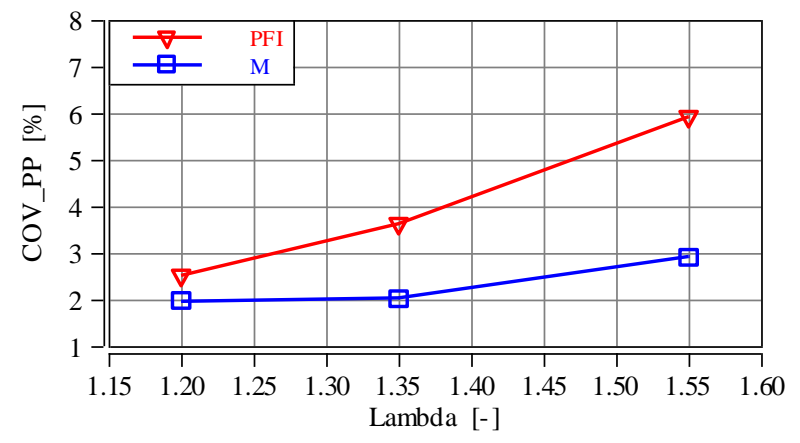

Fig. 8. Effects of injection system on coefficient of variation of peak pressure (PP) for different charge composition

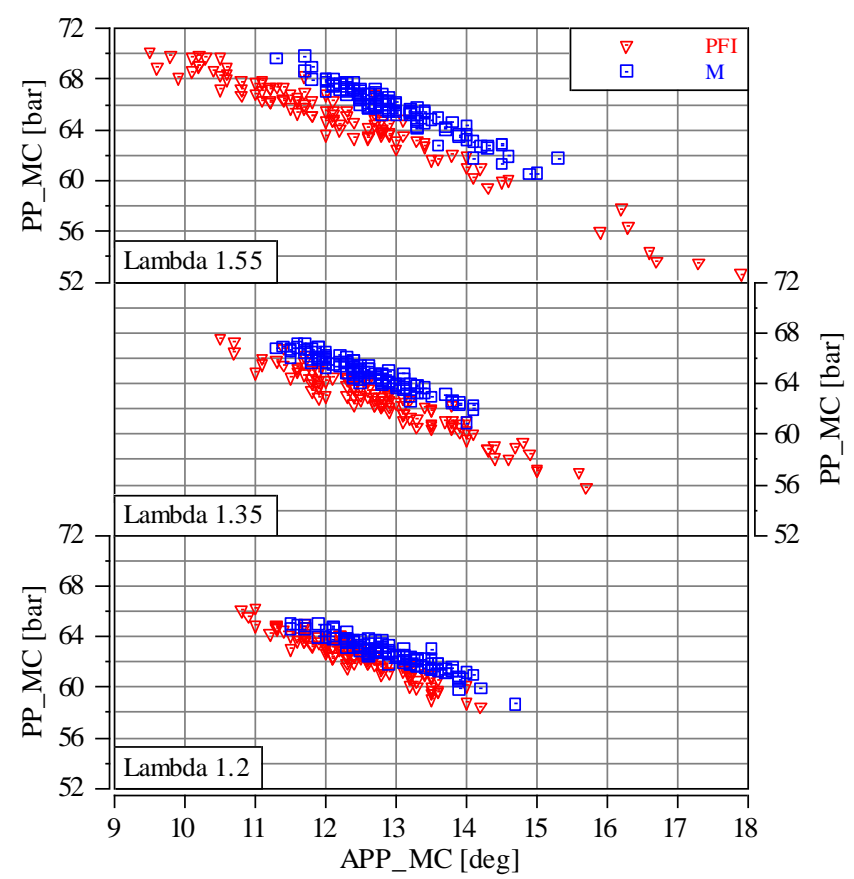

Fig. 9. Distribution of peak pressure points for three different lambda values

A more accurate analysis of the maximum combustion pressure is presented in the form of point maps, Fig. 9. The vertical axes show the maximum pressure values, the horizontal axis is the crankshaft angle CA at which the maximum pressure occurred. The later the pressure reached its maximum, the lower was its recorded value. This is due to the change in cylinder volume during the combustion stroke. The spread of data points increased with the increase of $\lambda$, this is especially visible with the PFI system.
The mixture richer in fuel has lower ignition requirements in relation to the lean mixtures. Despite the use of a highefficiency ignition mechanism in the PFI system, there still are data points where the combustion was abnormal $(\lambda=$ $=1.35-1.55)$. This was probably due to insufficient mixing of the fuel and air, leading to the creation of local areas that were very difficult to ignite.

Data regarding the combustion process duration refers to the amount of MBF relative to the crankshaft rotation angle. The results of the variable nature of the combustion process were shown as $\mathrm{COV}_{\mathrm{MBF} 50 \%}$ (Fig. 10) representing the center of combustion and $\mathrm{COV}_{\mathrm{MBF} 90 \%}$ (Fig. 11) representing the end of combustion. In both cases, the observed trends were the same as those previously discussed. The $\mathrm{COV}_{\mathrm{MBF90 \%}}$ value over the entire engine operating range was less than for $\mathrm{COV}_{\mathrm{MBF} 50 \% \text {. This proves that the process }}$ had higher repeatability in the second phase of combustion.

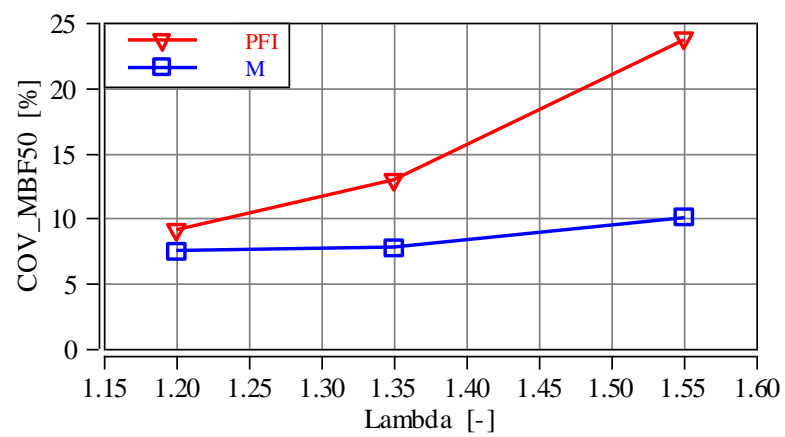

Fig. 10. Effects of injection system on coefficient of variation of $50 \%$ mass burned friction (MBF50\%) for different charge composition

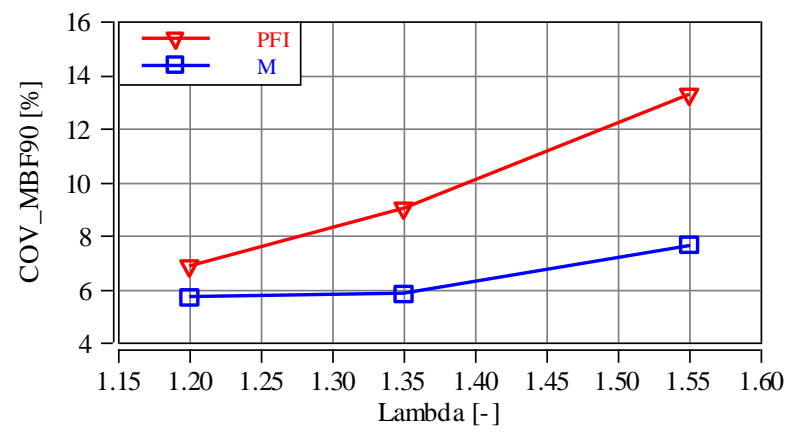

Fig. 11. Effects of injection system on coefficient of variation of $90 \%$ mass burned friction (MBF90\%) for different charge composition

As previously mentioned, the parameter relative to which the ignition timing was regulated for each test point was the center of combustion COC. The ignition timing was adjusted so that MBF50\% was $8^{\circ} \mathrm{CA}$ aTDC. Figure 12 shows the distribution of the MBF50\% values for the 100 registered engine cycles. While recording the engine operating parameters, the ignition system controller was set to generate a spark trigger signal at a constant time. A larger spread of values can be found when using the PFI system. In the conditions of lean mixture combustion, the difference between the minimum and maximum MBF50\% reached up to $9^{\circ} \mathrm{CA}$ compared to the $3.7^{\circ} \mathrm{CA}$ for the tested mixing system. 


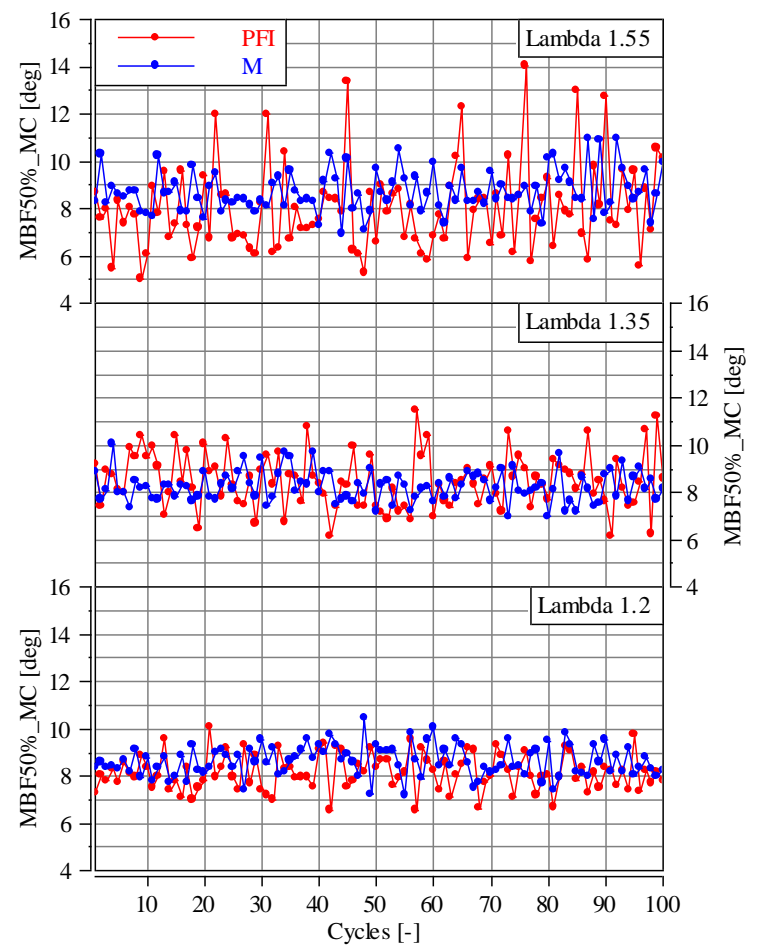

Fig. 12. Cycle by cycle variability of MBF50\% for three different lambda values

\section{Conclusion}

The results of research on the stability of a gas engine operation equipped with a modern two-stage combustion system have been presented in the paper. The analyzed solution was dedicated to LDV vehicles. The large amount of energy generated by the TJI (or spark-jet) ignition system allows to effectively ignite lean mixtures, which can be interpreted directly as a possibility of improving the engine's operating indicators. An important element affecting the engine operation is the mixture creation system. There- fore, two different methods of gaseous fuel injection were compared in this study.

The compared injection systems were characterized by different degrees of homogeneity of the created air-fuel mixtures. The use of CNG injection into the intake duct shortened the time available for mixing fuel with the air. As a result, the mixture is less homogeneous than the one obtained through the use of a mixer placed in the intake system.

The conducted research indicates the beneficial effects of combustion using more homogeneous mixtures on the repeatability of engine operation from one work cycle to the next. Lower $\mathrm{COV}_{\text {IMEP }}$ value for mixer fuel supply throughout the whole engine operating range was obtained from a statistical analysis of the results. In each of the analyzed cases, $\mathrm{COV}_{\text {IMEP }}$ was well below the value considered as a limit for stable engine operation. In the case of combustion of the mixture at $\lambda=1.2$ the difference was $23 \%$ while for $\lambda=1.55$ it was $14 \%$. The same trends were observed for the other indicators $\left(\mathrm{COV}_{\mathrm{PP}}, \mathrm{COV}_{\mathrm{MBF} 50 \%}, \mathrm{COV}_{\mathrm{MBF} 90 \%}\right)$. In addition, the use of a gas-air mixing support system allowed avoiding abnormal combustion in individual engine operating cycles. The disadvantage, however, was the presence of gaseous fuel in a significant volume of the intake system. This creates a risk of backfire as well as fuel leak directly to the exhaust system during the valve overlap timing.

\section{Acknowledgements}

This work was partially supported by the EU - Horizon 2020 (grant number 652816) performed within the years 2014-2019 and the investigations were extended with the support of the Subvention of Polish Ministry of Higher Education, project DS-PB 05/52/SBAD/0297.

\section{Nomenclature}

CA crank angle

CNG compressed natural gas

COV coefficient of variation

COC center of combustion

DI direct injection

IMEP indicated mean effective pressure

LDV light duty vehicle

MBF mass burned fraction

MC main chamber
PC pre-chamber

PFI port fuel injection

PP peak pressure

SI spark ignition

TJI turbulent jet ignition

TTW tank to wheel

$\lambda \quad$ air excess ratio

$\Phi$ equivalence ratio $(1 / \lambda)$

\section{Bibliography}

[1] BUESCHKE, W., SKOWRON, M., WISŁOCKI, K., SZWAJCA, F. Comparative study on combustion characteristics of lean premixed $\mathrm{CH}_{4}$ /air mixtures in $\mathrm{RCM}$ using spark ignition and turbulent jet ignition in terms of orifices angular position change. Combustion Engines. 2019, 176(1), 36-41. https://doi.org/10.19206/CE-2019-105

[2] CADAVID, Y., AMELL, A. The effect of natural gas composition and atmospheric humidity on premixed combustion across the regions of Colombia. Thermal Science and Engineering Progress. 2019, 10, 198-207.

https://doi.org/10.1016/j.tsep.2019.01.015

[3] CHEOLWOONG, P., SUNGWON, L., GIHUN, L. et al. Effect of mixer type on cylinder-to-cylinder variation and performance in hydrogen-natural gas blend fuel engine. International Journal of Hydrogen Energy. 2013, 38, 48094815. https://doi.org/10.1016/j.ijhydene.2013.01.079 
[4] CHIODI, M., FERRARI, A., MACK, O. et al. A way towards remarkable reduction of $\mathrm{CO}_{2}$-emissions in motorsports: the CNG-engine. SAE Technical Paper 2011-370006. 2011. https://doi.org/10.4271/2011-37-0006

[5] FARAMAWY, S., ZAKI, T., SAKR A.A.-E. Natural gas origin, composition, and processing: a review. Journal of Natural Gas Science and Engineering. 2016, 34, 34-54. https://doi.org/10.1016/j.jngse.2016.06.030

[6] GALLONI, E. Analyses about parameters that affect cyclic variation in a spark ignition engine. Applied Thermal Engineering. 2009, 29(5-6), 1131-1137.

https://doi.org/10.1016/j.applthermaleng.2008.06.001

[7] HUNICZ, J. Cycle-by-cycle variations in autonomous and spark assisted homogeneous charge compression ignition combustion of stoichiometric air-fuel mixture. International Journal of Spray and Combustion Dynamics. 2018, 10(3), 231-243. https://doi.org/10.1177/1756827718763564

[8] JI, S., LAN, X., CHENG, Y. et al. Cyclic variation of largebore multi point injection engine fuelled by natural gas with different types of injection systems. Applied Thermal Engineering. 2016, 102, 1241-1249.

https://doi.org/10.1016/j.applthermaleng.2016.03.082

[9] KRAMER, U., FERRERA, M., KUNNE, H. et al. Natural gas/methane fuels: European automotive fuel quality and standardization requirements. Gas Powered Vehicles Conference. Stuttgart 2015.

[10] LYONS, W.C, PLISGA, G.J., LORENZ, M.D. Standard handbook of petroleum and natural gas engineering. Chapter 7: Petroleum economic evaluation. Gulf Professional Publishing 2016.

https://doi.org/10.1016/B978-0-12-383846-9.00007-2

[11] MOON, S. Potential of direct-injection for the improvement of homogeneous-charge combustion in spark-ignition natural gas engines. Applied Thermal Engineering. 2018, 136, 41-48. https://doi.org/10.1016/j.applthermaleng.2018.01.068

[12] PATEL, R., BRAHMBHATT, P. Performance characteristics comparison of CNG port and CNG direct injection in spark ignition engine. European Journal of Sustainable Development Research. 2018, 2(2), 26.

https://doi.org/10.20897/ejosdr/82058

Filip Szwajca, MEng. - Faculty of Civil and Transport Engineering, Poznan University of Technology.

e-mail: Filip.Szwajca@put.poznan.pl
[13] PIELECHA, I., BUESCHKE, W., CIEŚLIK, W. et al. Turbulent spark-jet ignition in SI gas fuelled engine. MATEC Web of Conferences. 2017, 118, 00010-1-00010-10. https://doi.org/10.1051/matecconf/201711800010

[14] PIELECHA, I., BUESCHKE, W., SKOWRON, M. et al. Prechamber optimal selection for a two stage turbulent jet ignition type combustion system in CNG-fuelled engine. Combustion Engines. 2019, 176(1), 16-26. https://doi.org/10.19206/CE-2019-103

[15] REYES, M., TINAUT, F., GIMENEZ B. et al. Characterization of cycle-to-cycle variations in a natural gas spark ignition engine. Fuel. 2015, 140, 752-761. https://doi.org/10.1016/j.fuel.2014.09.121

[16] SCHUMACHER, M., WENSING, M. A gasoline fuelled pre-chamber ignition system for homogeneous lean combustion processes. SAE Technical Paper 2016-01-2176. 2016. https://doi.org/10.4271/2016-01-2176

[17] SHI, J., WANG, T., ZHAO, Z. et al. Cycle-to-cycle variation of a diesel engine fueled with Fischer-Tropsch fuel synthesized from coal. Applied Sciences. 2019, 9, 2032. https://doi.org/10.3390/app9102032

[18] SINGOTIA, P.K., SARASWATI, S. Cycle-by-cycle variations in a spark ignition engine fueled with gasoline and natural gas. IOP Conference Series: Materials Science and Engineering. 2019, 691, 012061. https://doi.org/10.1088/1757899X/691/1/012061

[19] SONG, J., CHOI M., PARK, S. Comparisons of the volumetric efficiency and combustion characteristics between CNG-DI and CNG-PFI engines. Applied Thermal Engineering. 2017, 121, 595-603.

https://doi.org/10.1016/j.applthermaleng.2017.04.110

[20] STONE, R. Introduction to internal combustion engines. Macmillan International Higher Education. 2012. 135.

[21] SYROVATKA, Z., VITEK, O., VAVRA, J. et al. Scavenged pre-chamber volume effect on gas engine performance and emissions. SAE Technical Paper 2019-01-0258. 2019. https://doi.org/10.4271/2019-01-0258

[22] TOULSON, E., SCHOCK, H., ATTARD, W. A review of pre-chamber initiated jet ignition combustion systems. SAE Technical Paper 2010-01-2263. 2010. https://doi.org/10.4271/2010-01-2263

Prof. Krzysztof Wisłocki, DSc., DEng. - Faculty of Civil and Transport Engineering, Poznan University of Technology.

e-mail: Krzysztof.Wislocki@put.poznan.pl 